\title{
The quality of home spirometry in school children with asthma
}

D C Wensley, M Silverman

\begin{abstract}
Background-Handheld electronic spirometers provide the opportunity for more comprehensive monitoring of lung function at home than has hitherto been available. The aim of this study was to assess the quality of spirometric data collected at home by 90 asthmatic schoolchildren aged 7-14 years.

Methods-After training, children carried out twice daily recordings at home for four consecutive periods of 4 weeks using a data storage spirometer (Vitalograph), encouraged by 4-weekly visits from a research nurse. Compliance (proportion of blows recorded at correct time of day), technical quality (by machine criteria), and valid data recorded (the multiple of compliance and technical ability) were assessed.

Results-Mean compliance declined from $81.4 \%$ to $70.4 \%(p<0.001)$ between the first and last month, although the technical quality of the manoeuvres $(81.9 \%$ and $80.1 \%$, respectively) did not change significantly $(\mathrm{p}=0.48)$.

Conclusions-There was a steady reduction of valid data over the four periods (from $73.6 \%$ to $64.3 \%, 59.7 \%$, and $57.6 \%$ ) with wide individual differences. Even under ideal conditions, home spirometry provides an incomplete (and therefore potentially biased) picture of long term changes in pulmonary function.

(Thorax 2001;56:183-185)
\end{abstract}

Keywords: asthma; children; home monitoring; peak expiratory flow; compliance

Domiciliary peak expiratory flow (PEF) measurement is widely used to monitor asthma although its validity in children has been questioned. ${ }^{12}$ The relevance of PEF measurement and its accuracy have been called into question. ${ }^{3}$ Compliance with PEF monitoring has been investigated in adults revealing discrepancies between diary card recordings and electronically recorded results. ${ }^{4}$ It is possible that spirometric tests could provide more accurate and clinically relevant information than PEF to guide self-management, although not necessarily with greater compliance.

Spirometers are widely used in clinical practice, providing easy access to more detailed information about lung function. With increased portability it is feasible to carry out spirometric monitoring in the home for clinical or research purposes. ${ }^{6}$ Training for spirometric testing is important ${ }^{7}$ as a potential reduction in spirometric values may occur with suboptimal effort or inaccurate techniques. ${ }^{89}$ This calls into question the validity of unsupervised measurements at home.

The objective of this study was to determine the ability of schoolchildren to carry out spirometric manoeuvres unsupervised at home. The aims were to assess compliance, technical quality of recordings, and the amount of valid information obtained. The effect of implementing volume reproducibility criteria ${ }^{70}$ instead of percentage variability ${ }^{11}$ on the quality and quantity of data collected was also investigated.

\section{Methods}

PATIENTS

Ninety children with asthma of median age 11 years (range 7-14) were recruited from hospital clinics and general practices in the locality. All subjects were physician diagnosed asthmatics in receipt of regular anti-inflammatory treatment, at least at step 2 of the British asthma management guidelines. ${ }^{12}$ Children were excluded if they were unable to perform spirometric tests after suitable training or had taken systemic steroids within 1 month of recruitment. All participants and their parents gave written informed consent and the study had ethical approval from the Leicestershire research ethics committee.

\section{STUDY DESIGN}

The data reported here were collected as part of a randomised controlled trial of PEF monitoring in guided self-management. Spirometric data were simultaneously recorded, blind to the participants. Each child was required to complete twice daily spirometric tests for 16 weeks, together with other measures to monitor their condition. At the first home visit they were taught to perform a forced vital capacity (FVC) manoeuvre and to use the electronic spirometer (Data Storage Spirometer, Vitalograph, Buckingham, UK). They were subsequently visited every 4 weeks to check ability, to retrain if needed, and to download data from the spirometer. At the end of a 4 week assessment period the children were randomly assigned in blocks of 10 into one of two groups: symptom + PEF based self-management $(n=44)$ or symptom based management alone $(n=46)$. In the former group the spirometer was programmed to display PEF, while for the latter it did not.

\section{EOUIPMENT}

The spirometer recorded values of forced vital capacity (FVC), forced expiratory volume in one second $\left(\mathrm{FEV}_{1}\right), \mathrm{PEF}$, and lower flows $\left(\mathrm{FEF}_{25}\right.$ and $\left.\mathrm{FEF}_{25-75}\right)$ using a flowhead based on 
Table 1 Anthropometric data

\begin{tabular}{ll}
\hline Median (range) age (years) & $11(7-14)$ \\
Male (\%) & 53.3 \\
Family history of asthma (\%) & 42 \\
Median (range) age at diagnosis (years) & $4(0.25-12)$ \\
Severity (>BTS step 2) (\%) & 24.4 \\
Hospitalised for asthma (\%) & 38.9
\end{tabular}

BTS $=$ British Thoracic Society guidelines. ${ }^{12}$

a Fleisch-type pneumotachograph. Each spirometer was calibrated between subjects using a 1 litre syringe (accurate to within $\pm 1 \%$ ) through a plastic adult mouthpiece.

A mouthpiece with a one way valve (Vitalograph, Buckingham, UK) was used by each child to prevent inhalation via the mouthpiece. Only expiratory manoeuvres were collected in this study. Nose clips were not used. The subjects were required to blow between two and five times until two blows within $5 \%$ of FVC + $\mathrm{FEV}_{1}$ were produced. The single "best test" with largest FVC + FEV 1 was stored by the machine. The machine marked technically acceptable blows (where the two best blows were within $5 \%$ of each other for FVC + $\mathrm{FEV}_{1}$ ). If a session failed to meet these reproducibility criteria, the difference (\%) between the two best blows was recorded. The date and time of each session was logged by the machine and the children were fully aware of this assessment of compliance.

DATA ANALYSIS

The data were analysed using SPSS 6.0 (SPSS Inc, Chicago, Illinois, USA). Compliance was defined as the proportion of expected manoeuvres which were performed at the correct time. Technical quality represented the proportion of technically acceptable manoeuvres defined either according to the American Thoracic Society 1987 criteria $(<5 \%)$ or if a fixed maximum volume difference was applied $(200 \mathrm{ml}$, $400 \mathrm{ml}){ }^{7}$ Valid data were the multiples of technically acceptable blows and compliance. Repeated measures analysis of variance was used to determine within and between subject differences in each measure over time. Paired $t$ tests were used to assess the difference in each measure between weeks 1 and 4 of the study.

\section{Results}

Ninety eligible children agreed to enter the study and were randomised (table 1). One child from the symptom only group refused to participate following randomisation and was withdrawn from the study. Data are presented for 89 children after randomisation. There were no differences in compliance or technical ability and therefore in the amount of valid data between the groups with and without a visual display of PEF, so the results are presented for the whole study population. The chance excess

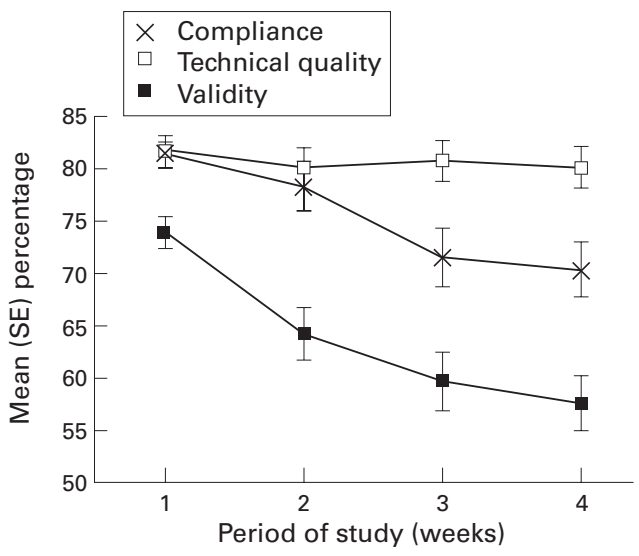

Figure 1 Mean (SE) percentage compliance, technical quality, and validity of spirometric results over the four periods of 4 weeks of the study.

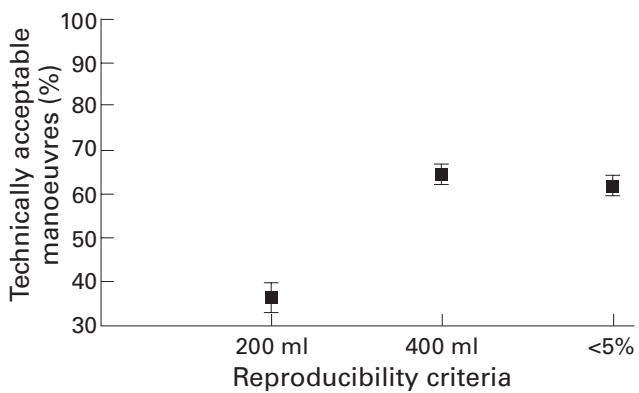

Figure 2 Effect of reproducibility criteria on technical quality of mean (SE) FVC manoeuvres (\%).

of boys in the peak flow group ( $68 \%$ versus $39 \%, p=0.005$ ) was adjusted for in the analysis. Children became less compliant with time ( $p<0.001$; fig 1) but the mean results hid a wide variation in compliance (29.7-96.6\%). There was a tendency for each child's compliance to be consistent throughout the study. The technical quality of data, where within-session reproducibility reached the $<5 \%$ criterion, was maintained throughout the study period although there were wide individual differences (fig 1). As a result of reduced compliance, the amount of valid data declined with time ( $p<0.001$; fig 1, table 2).

Recent ATS guidelines use fixed volume reproducibility criteria. ${ }^{7}$ Applying a fixed volume criterion of $400 \mathrm{ml}\left(\mathrm{FVC}+\mathrm{FEV}_{1}\right)$ made very little difference to the amount of data deemed technically acceptable, although a stricter volume of $200 \mathrm{ml}$ would have greatly reduced the proportion of technically acceptable manoeuvres (fig 2).

\section{Discussion}

These data show that the main cause of the steady decline in valid data obtained from children during home spirometric testing is falling compliance rather than loss of skill. Compli-

Table 2 Mean (SE) data available for each period of study (\%)

\begin{tabular}{|c|c|c|c|c|c|c|c|c|}
\hline & \multicolumn{4}{|c|}{ PEF based management group } & \multicolumn{4}{|c|}{ Symptom based management group } \\
\hline & 1-4 weeks & 5-8 weeks & 9-12 weeks & 13-16 weeks & 1-4 weeks & 5-8 weeks & 9-12 weeks & 13-16 weeks \\
\hline Compliance & $81.50(2.05)$ & $81.69(3.08)$ & $74.64(3.86)$ & $70.58(3.88)$ & $81.27(1.74)$ & $75.02(3.50)$ & 68.25 & $70.11(3.72)$ \\
\hline Technical ability & $82.71(2.15)$ & $79.87(2.81)$ & $83.51(2.66)$ & $81.43(2.45)$ & $80.61(2.24)$ & $80.60(2.52)$ & $78.07(2.78)$ & $78.90(3.08)$ \\
\hline Valid data & $67.54(2.51)$ & $67.25(3.35)$ & $64.51(3.82)$ & $59.48(3.69)$ & $66.04(2.47)$ & $61.35(3.73)$ & $54.84(4.05)$ & $55.60(3.85)$ \\
\hline
\end{tabular}


ance in our sample deteriorated month by month, leading to a continual decline in the amount of valid data. This was the case despite the fact that the children were aware that they were being monitored and whether or not any of the lung function data were accessible to the children. Technical ability remained constant throughout the study.

Compliance with monitoring and treatment is a major issue in asthma management and its measurement is difficult. Electronic recording is a means of assessing compliance and in research studies is often covert. ${ }^{4}$ Covert compliance assessment of PEF monitoring in a group of inner city children demonstrated that, even over a short period of time, compliance declined significantly. ${ }^{13}$ The same study also suggested that manual records significantly overestimate compliance compared with electronic records. This has also been found in adults. ${ }^{4}$ Pelkonen et al reported 94\% compliance with spirometric tests over a mean period of 24 days in newly diagnosed asthmatic children, but it is not reported whether this assessment was covert. ${ }^{6}$ Our data $(81.4 \%$ during the first 28 day period) are poorer than this. The children in our study were not newly diagnosed asthmatics, which perhaps reduced the novelty.

Test performance is an important factor so that comprehensive training is essential. ${ }^{7}$ The quality of manoeuvres was automatically assessed according to ATS criteria ${ }^{7}$ and over $80 \%$ of manoeuvres were technically acceptable. Technical skill did not change systematically although there was increasing variability between children with time. It may be affected by illness or inexperience with testing. ${ }^{9}$ Other studies have reported excellent within session reproducibility ${ }^{9}$ although, with a greater number of younger children, the proportion of successful manoeuvres may be lower than that observed in this study. ${ }^{6}$ The DSS stores only the best manoeuvre and provides percentage variability in FVC $+\mathrm{FEV}_{1}$ between the two best blows. This is the only measure of within session reproducibility. There is no measure of within session reproducibility for PEF.

A learning effect has been suggested during PEF measurement ${ }^{14}$ and spirometric testing ${ }^{15}$ but we did not see any improvement in technical quality with time.

The ATS now provide fixed volume criteria for reproducibility ${ }^{7}$ as a means of reducing the number of younger and shorter patients excluded on the previous criteria. ${ }^{10}$ The criteria apply a $200 \mathrm{ml}$ goal for reproducibility to both FVC and $\mathrm{FEV}_{1}$, not the sum. Application of a $200 \mathrm{ml}$ criteria to the sum is rigorous and allows very little variability in either of these measures. Although $400 \mathrm{ml}$ may seem generous, in our data set it was commensurate with the $5 \%$ machine criteria.

Our results therefore suggest that it is possible to record spirometric parameters in school children at home, unsupervised following comprehensive training. Although children remain technically able to perform the manoeuvre, reduced compliance leads to a significant reduction in valid data over time. The optimal time for collecting spirometric data at home is 4 weeks.

This work was funded by the National Asthma Campaign. The authors would like to thank Dr John Thompson for statistical advice.

1 Uwyyed K, Springer C, Avital A, et al. Home recording of PEF in young aringer C, Avital A, et al. Home recording of $\mathrm{PEF}$ in young asthmatics: does
ment? Eur Respir $\mathcal{F} 1996 ; 9: 872-9$.

2 Charlton I, Charlton G, Broomfield J, et al. Evaluation of peak flow and symptoms only self management plans for control of asthma in general practice. BMF 1990;301: $1355-9$

3 Miller MR, Dickinson SA, Hitchings DJ. The accuracy of portable peak flow meters. Thorax 1992;47:904-9.

4 Chowienczyk PJ, Parkin DH, Lawson CP, et al. Do asthmatic patients correctly record home spirometry measurements? BMF 1994;309:1618.

5 Hyland ME, Kenyon CA, Allen R, et al. Diary keeping in asthma: comparison of written and electronic methods. asthma: comparison

6 Pelkonen AS, Nikander K, Turpeinen M. Reproducibility of home spirometry in children with newly diagnosed asthma. Pediatr Pulmonol 2000;29:34-8.

7 American Thoracic Society. Standardization of spirometry, 1994 update. Am f Respir Crit Care Med 1995;152:110736.

8 Tzelepis GE, Zakynthinos S, Vassilakopoulos T, et al. Inspiratory maneuver effects on peak expiratory flow: role of elastic recoil and expiratory pressure. Am $\mathcal{7}$ Respir Crit Care Med 1997;156:1399-404.

9 Studnicka M, Frischer T, Neumann M. Determinants of reproducibility of lung function tests in children aged 7 to reproducibility of lung function tests in child

10 Hankinson JL, Bang KM. Acceptability and reproducibility criteria of the Amercian Thoracic Society as observed in a sample of the general population. Am Rev Respir Dis 1991; 143:516-21

11 American Thoracic Society. Standardization of spirometry: 1987 update. Am Rev Respir Dis 1987;136:1285-98.

12 British Thoracic Society, National Asthma Campaign, Royal College of Physicians of London, et al. The British guidelines on asthma management: 1995 review and position statement. Thorax 1997;52(Suppl 1):S1-21.

13 Redline S, Wright EC, Kattan M, et al. Short-term compliance with peak flow monitoring: results from a study of inner city children with asthma. Pediatr Pulmonol 1996;21: inner city

14 Gannon PF, Belcher J, Pantin CF, et al. The effect of patient technique and training on the accuracy of self-recorded peak expiratory flow. Eur Respir f 1999;14:28-31.

15 Brunekreef B, Hoek G. Time trends in repeated spirometry in children. Eur Respir f 1992;5:553-9. 